\title{
Plasma lipids and lipoprotein cholesterol concentrations in people with different diets in Britain
}

\author{
M THOROGOOD， R CARTER， L BENFIELD， KLIM MCPHERSON， J I MANN
}

\begin{abstract}
Concentrations of total cholesterol and cholesterol in the various lipoprotein fractions were measured in vegans, vegetarians, fish eaters (who did not eat meat), and meat eaters. Total and low density lipoprotein cholesterol concentrations were higher in meat eaters than vegans, with vegetarians and fish eaters having intermediate and similar values. High density lipoprotein cholesterol concentration was highest in the fish eaters but did not differ among the other groups. There were striking trends with age in total and low density lipoprotein cholesterol concentrations, which differed between men and women: women showed a steady increase in concentration with age, whereas concentrations in men did not increase appreciably after the age of 40 , which may partly explain sex differences in the prevalence of coronary heart disease.
\end{abstract}

The differences in total cholesterol concentration suggest that the incidence of coronary heart disease may be $24 \%$ lower in lifelong British vegetarians and $57 \%$ lower in lifelong vegans than in meat eaters.

\section{Introduction}

Differences in blood cholesterol concentrations explain much of the cross cultural variation in the prevalence of coronary heart disease. ${ }^{1}$ In high risk populations there is a linear association between cholesterol concentrations and the incidence of coronary heart disease. ${ }^{2}$ The proportion of energy intake derived from saturated fat is an important determinant of differences in blood cholesterol

\footnotetext{
Department of Community Medicine and General Practice and Diabetes Research Laboratories, Radcliffe Infirmary, Oxford OX2 6HE

M THOROGOOD, BSC, research officer

R CARTER, MIST, senior medical laboratory scientific officer

L BENFIELD, medical laboratory scientific officer

KLIM MCPHERSON, PHD, university lecturer in medical statistics

J I MANN, DM, PHD, university lecturer and honorary consultant physician

Correspondence to: Dr Mann.
}

concentration among populations. ${ }^{1}$ In epidemiological studies of people in populations with high prevalences of coronary heart disease, however, the effect of dietary factors on lipid concentrations is less striking. ${ }^{3}$ Several studies have shown lower cholesterol concentrations in vegetarians than in those who eat meat, ${ }^{4.6}$ but few data are available for vegans and fish eaters. Vegetarian diets and high intakes of fish are associated with reduced risk of coronary heart disease. ${ }^{7 \cdot 10} \mathrm{We}$ collected blood samples from vegans, vegetarians, fish eaters, and meat eaters to study in more detail the effect of diet on lipoprotein cholesterol concentrations in the British population, in whom cholesterol concentrations and the prevalence of coronary heart disease are among the highest in the world.

\section{Subjects and methods}

Six thousand subjects who do not eat meat and 5000 meat eating controls are participating in a nationwide long term prospective study. Initially, members of the Vegetarian Society of the United Kingdom were invited to participate. Later a further request for volunteers was made by advertisements in various publications and on national and local radio. The control group consists of meat eating friends and relatives of those who do not eat meat. Recruitment took place from September 1980 to January 1984. From April 1984 to January 1986 all participants under the age of 70 were sent a kit consisting of a $10 \mathrm{ml}$ heparinised tube, a syringe, and explanatory letters to them and their general practitioners. Doctors and their staff were requested to obtain a blood sample, which was sent by post to our laboratory in the special package provided. At the time of writing blood samples had been received from 114 vegans, 1550 lacto-ovovegetarians, 415 fish eaters (who did not eat meat), and 1198 meat eaters. Participants were allocated to these dietary groups on the basis of data obtained from a simple questionnaire completed on entry to the study.

On arrival in the laboratory blood samples were spun down and total cholesterol concentrations and concentrations of cholesterol in the various lipoprotein subfractions measured with a Technicon autoanalyser (second generation). Plasma was diluted and total cholesterol concentration measured directly by the cholesterol oxidase peroxidase antiperoxidase enzymatic method. Two further aliquots of plasma were taken; in one aliquot very. low density lipoprotein and low density lipoprotein were precipitated by the heparin-manganese method, so that high density lipoprotein cholesterol could be measured in the supernatant. In the other aliquot very low density lipoprotein was precipitated with sodium dodecylsulphate, leaving high and low density lipoproteins in solution. Quantities of cholesterol in the various subfractions were calculated by subtraction. 
Triglyceride concentrations were not measured because blood samples were not collected under standard (fasting) conditions. We have shown previously that lipid analyses may be made successfully on blood samples sent by first class post. ${ }^{11}$

TABLE I-Numbers in each age group by diet and sex

\begin{tabular}{|c|c|c|c|c|c|c|c|c|}
\hline \multirow{2}{*}{$\begin{array}{c}\text { Age } \\
\text { group } \\
\text { (years) }\end{array}$} & \multicolumn{4}{|c|}{ Men } & \multicolumn{4}{|c|}{ Women } \\
\hline & Vegan & Vegetarian & $\begin{array}{l}\text { Fish } \\
\text { eater }\end{array}$ & $\begin{array}{l}\text { Meat } \\
\text { eater }\end{array}$ & Vegan & Vegetarian & $\begin{array}{l}\text { Fish } \\
\text { eater }\end{array}$ & $\begin{array}{l}\text { Meat } \\
\text { eater }\end{array}$ \\
\hline $\begin{array}{l}\leqslant 29 \\
30-39 \\
40-49 \\
50-59 \\
\geqslant 60\end{array}$ & $\begin{array}{r}14 \\
19 \\
3 \\
7 \\
2\end{array}$ & $\begin{array}{r}147 \\
152 \\
74 \\
69 \\
59\end{array}$ & $\begin{array}{r}33 \\
54 \\
18 \\
7 \\
10\end{array}$ & $\begin{array}{r}99 \\
171 \\
89 \\
66 \\
61\end{array}$ & $\begin{array}{r}28 \\
15 \\
10 \\
11 \\
5\end{array}$ & $\begin{array}{r}383 \\
280 \\
142 \\
148 \\
96\end{array}$ & $\begin{array}{r}78 \\
103 \\
58 \\
36 \\
18\end{array}$ & $\begin{array}{r}175 \\
233 \\
120 \\
101 \\
83\end{array}$ \\
\hline Total & 45 & 501 & 122 & 486 & 69 & 1049 & 293. & 712 \\
\hline
\end{tabular}

TABLE II-Mean age (years) by sex and diet

\begin{tabular}{lcc}
\hline Diet & Men & Women \\
\hline Vegan & $36 \cdot 2$ & $37 \cdot 1$ \\
Vegetarian & $39 \cdot 1$ & $37 \cdot 3$ \\
Fish eater & $36 \cdot 8$ & $37 \cdot 8$ \\
Meat eater & $40 \cdot 6$ & $40 \cdot 0$ \\
\hline
\end{tabular}

TABLE III-Mean (SE) concentrations (mmolll) of total cholesterol, low density lipoprotein cholesterol, and high density lipoprotein cholesterol adjusted for age and sex and ratio of low density lipoprotein cholesterol concentration to high density lipoprotein cholesterol concentration by diet

\begin{tabular}{|c|c|c|c|c|}
\hline Diet & $\begin{array}{c}\text { Total } \\
\text { cholesterol }\end{array}$ & $\begin{array}{l}\text { Low density } \\
\text { lipoprotein } \\
\text { cholesterol }\end{array}$ & $\begin{array}{l}\text { High density } \\
\text { lipoprotein } \\
\text { cholesterol }\end{array}$ & $\begin{array}{l}\text { Low density lipoprotein } \\
\text { cholesterol:high density } \\
\text { lipoprotein cholesterol }\end{array}$ \\
\hline $\begin{array}{l}\text { Vegan } \\
\text { Vegetarian } \\
\text { Fish eater } \\
\text { Meat eater }\end{array}$ & $\begin{array}{l}4 \cdot 29(0 \cdot 140) \\
4 \cdot 88(0 \cdot 100) \\
5 \cdot 01(0 \cdot 109) \\
5 \cdot 31(0 \cdot 101)\end{array}$ & $\begin{array}{l}2 \cdot 28(0 \cdot 126) \\
2 \cdot 74(0 \cdot 090) \\
2 \cdot 88(0 \cdot 098) \\
3 \cdot 17(0.091)\end{array}$ & $\begin{array}{l}1.49(0.048) \\
1.50(0.035) \\
1.56(0.038) \\
1.49(0.035)\end{array}$ & $\begin{array}{l}1.63(0.120) \\
1.95(0.086) \\
1.97(0.093) \\
2.27(0.087)\end{array}$ \\
\hline
\end{tabular}

\section{Results}

Table I shows the numbers of men and women in the different dietary groups and table II their mean ages. Table III shows the concentrations of total, low density lipoprotein, and high density lipoprotein cholesterol adjusted for age and sex and the ratio of low density lipoprotein to high density lipoprotein cholesterol concentration. Total and low density lipoprotein cholesterol concentrations were higher in the meat eaters than in all other groups. Concentrations in the vegans were significantly lower than those in vegetarians and fish eaters, who had similar values. High density lipoprotein cholesterol concentrations were significantly higher in the fish

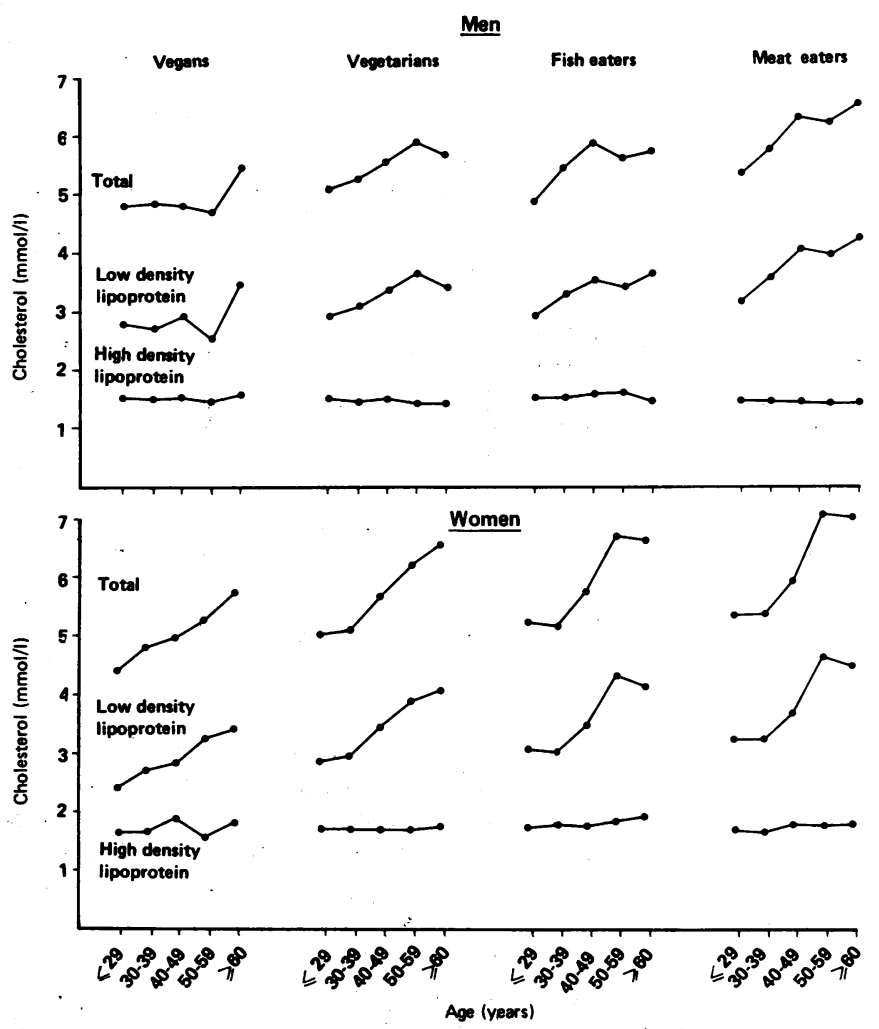

Mean cholesterol concentrations in men and women.

TABLE IV_Significance of effect of each factor on concentrations of total cholesterol, low density lipoprotein cholesterol, and high density lipoprotein cholesterol and ratio of low density lipoprotein cholesterol concentration to high density lipoprotein cholesterol concentration

\begin{tabular}{|c|c|c|c|c|c|c|}
\hline \multirow[b]{2}{*}{ Factor } & \multirow{2}{*}{\multicolumn{2}{|c|}{ df }} & \multicolumn{4}{|c|}{ F Value (p) } \\
\hline & & & Total cholesterol & $\begin{array}{c}\text { Low density } \\
\text { lipoprotein cholesterol }\end{array}$ & $\begin{array}{c}\text { High density } \\
\text { lipoprotein cholesterol }\end{array}$ & $\begin{array}{l}\text { Low density lipoprotein cholesterol:high density } \\
\text { lipoprotein cholesterol }\end{array}$ \\
\hline
\end{tabular}

Statistical methods-Ages were categorised into five groups for statistical analyses: 29 and less, 30-39, 40-49, 50-59, and 60 and over. Age, sex, and diet (four groups) were fitted into a linear model successively with interactions after the main effects of each factor. ${ }^{12}$ Thus for total, low density lipoprotein, and high density lipoprotein cholesterol concentrations and the ratio of low density lipoprotein to high density lipoprotein cholesterol concentration the effects of age, sex, and their interaction were fitted first. Then an independent (that is, standardised for age and sex) effect of diet on these values was fitted and tested. Finally, we fitted a full model to test for an effect of diet on the age and sex relation. Preliminary examinations of the data indicated that the lipid concentrations were more nearly Gaussian after a logarithmic transformation, ${ }^{13}$ and therefore all significance tests were conducted with logarithmic transformations. eaters compared with the three other diet groups. The figure shows the effects of age and sex on these lipid concentrations in the four dietary groups. Table IV summarises the significance of the influence of the various factors on the cholesterol concentrations. The $p$ values quoted apply to tests of heterogeneity, and thus for the row labelled diet the test was of differences between all four diets. For the row labelled, for instance, age $\times$ sex the test was for an interaction of age with sex after adjustment for age and sex separately; thus the test was for a different effect of age between the sexes. For most groups there was a characteristic increase with age in concentrations of total and low density lipoprotein cholesterol: women tended to show a continuous increase with age, whereas concentrations in men did not increase appreciably after the age of 40 . In younger age groups men had higher concentrations than women, whereas in the older groups this 
difference was reversed, resulting in similar mean concentrations for men and women overall. On the other hand, high density lipoprotein cholesterol concentrations were higher in women (mean $1.72 \mathrm{mmol} / \mathrm{l})$ than men $(1.47$ $\mathrm{mmol} / \mathrm{l}$ ) but did not show any trends with age. Despite the profound differences in concentrations of total and low density lipoprotein cholesterol among the diet groups, diet did not have a significant influence on the effects of age and sex described above. In vegan men there did not seem to be any increase up to the age of 60 , but the numbers in each age group were small and insufficient for us to be certain.

\section{Discussion}

Rural Africans, Asians, and other people whose diets are low in saturated fat and animal protein and high in complex carbohydrate have low blood cholesterol concentrations and prevalences of coronary heart disease. ${ }^{14}$ Mediterranean populations also have lower cholesterol concentrations and prevalences of coronary heart disease than those in Britain, perhaps because their diet is high in monounsaturated and polyunsaturated fatty acids. ${ }^{15}$ Although various dietary manipulations (reducing saturated fat intake, increasing the ratio of polyunsaturated or monounsaturated fatty acid intake to saturated fatty acid intake, or increasing intake of soluble fibre) can reduce blood cholesterol concentrations, ${ }^{16}$ relatively few studies have shown an association between dietary characteristics and lipid concentrations within populations. ${ }^{3}$ Shekelle $e t a l$, however, found a relation between blood cholesterol concentration and the ratio of polyunsaturated fatty acid intake to saturated fatty acid intake; various dietary scores that described fat intake were also related to cholesterol concentrations. ${ }^{17}$

Our data confirm the findings of several other studies that lower concentrations of total and low density lipoprotein cholesterol are found in vegetarians than in meat eaters. ${ }^{46}$ In addition, we showed that those who regularly ate fish (but no meat) had concentrations similar to those in vegetarians and that vegans had lower concentrations than those in any of the other dietary groups. These differences were not explained by differences in the age and sex structures of the groups. Apart from the obvious differences in intakes of animal protein, vegetarians and vegans have higher intakes of dietary fibre and total carbohydrate and a higher ratio of polyunsaturated fatty acid intake to saturated fatty acid intake than meat eaters. The participants in this study were volunteers who agreed to complete a dietary questionnaire and give a blood sample; such people are not necessarily representative of the dietary groups from which they are drawn. In particular, the meat eaters used alcohol and tobacco less than the general population and may well also have had a healthier diet; this, however, would probably have reduced rather.than increased the differences in blood lipid concentrations among the diet groups. All these dietary characteristics may contribute to the low concentrations of total and low density lipoprotein cholesterol, which might, in turn, partly explain the reduced standardised mortality ratios for coronary heart disease observed in American ${ }^{7}$ and Dutch ${ }^{8}$ Seventh Day Adventists (most of whom are vegetarian) and British vegetarians. ${ }^{9}$

High concentrations of high density lipoprotein cholesterol may help to protect some people in high risk populations against coronary heart disease, although data from the British regional heart study have not shown high density lipoprotein cholesterol concentration to be an independent risk factor for ischaemic heart disease. ${ }^{18}$ The finding of similar concentrations in vegans, vegetarians, and meat eaters suggests that high concentrations of high density lipoprotein cholesterol might be less important when concentrations of low density lipoprotein cholesterol are low. Kromhout et al showed an inverse relation between risk of coronary heart disease and the amount of fish eaten ${ }^{10}$; the higher concentration of high density lipoprotein cholesterol that we found in fish eaters might partly account for this.

Blood cholesterol concentration has been shown to increase with age in several studies carried out in affluent societies. The size of the groups in this study allowed, for the first time, the effects of age and sex on concentrations of total and low density lipoprotein cholesterol in different dietary groups to be examined. In the younger age groups women had lower concentrations than men. In all dietary groups, however, women showed a steep and continuous rise with age up to the age of 60 , whereas concentrations in men did not increase appreciably after the age of 40 , so that after 50 concentrations were higher in women than men in all groups. Whether this was a cohort effect as opposed to a physiological effect of age is difficult to determine in a single cross sectional study. This sex difference, which has also been shown in other studies, ${ }^{19}$ may in part be due to the change in hormonal state at the time of the menopause, although the study by McPherson et al found no difference between premenopausal and postmenopausal women of similar age. ${ }^{20}$ Miller suggested that a defect in activity of the low density lipoprotein receptor acquired in healthy subjects during aging may contribute substantially to the incidence of coronary heart disease. ${ }^{21}$ This does not, however, account for the sex differences we observed, which may partly explain the sharp increase in the incidence of coronary heart disease in women after the menopause.

Recent data have suggested that a $10 \%$ reduction in cholesterol concentration might be associated with a $30 \%$ reduction in the incidence of coronary heart disease. ${ }^{2}$ Our data suggest that in Britain the incidence of coronary heart disease may be $24 \%$ lower in lifelong vegetarians and $57 \%$ lower in lifelong vegans than in meat eaters. Follow up of the groups we studied may confirm this, as well as providing an opportunity of studying further the relation between low cholesterol concentrations and the incidence of cancer.

The study was supported by a grant from the Cancer Research Campaign. We thank the volunteers and their doctors and Mrs M Houlistan, Mrs J White, and Mrs A Reeve, for administrative and secretarial help.

\section{References}

1 Keys A. Seven countries: a multivariate analysis of death and coronary heart disease. Cambridge, Massachusetts: Harvard University Press, 1980.

2 Martin MJ, Hulley SB, Browner WS, Kuller LH, Wentworth D. Serum cholesterol, blood pressure and mortality: implications from a cohort of 361662 men. Lancet 1986;ii:933-6. Anonymous. Soft fat-harder evidence. [Editorial.] Lancet 1981 ;i:597-8.

4 Gear JS, Mann JI, Thorogood M, Carter R, Jelfs R. Biochemical and haematological variables in vegetarians. BrMed f. 1980;280:1415.

5 Sacks FM, Castelli WP, Donner A, Kass EH. Plasma lipids and lipoproteins in vegetarians and controls. N Engl f Med 1975;292:1148-51.

6 Burr ML, Bates CJ, Fehily AM, St Leger AS. Plasma cholesterol and blood pressure in vegetarians. F Hum Nutr 1981;35:437-41.

7 Phillips RL, Lemon FR, Beeson WL, Kuzma JW. Coronary heart disease mortality among Seventh-Day Adventists with differing dietary habits: a preliminary report. Am f Clin Nutr 1978;31(suppl 10): 191-8S.

8 Berkel J, De Waard F. Mortality pattern and life expectancy of Seventh Day Adventists in the Netherlands. Int $\mathcal{F}$ Epidemiol 1983;12:455-9.

9 Burr ML, Sweetnam PM. Vegetarianism, dietary fibre and mortality. Am $f$ Clin Nutr 1982;36:873-7.

10 Kromhout D, Bosschieter EB, Coulander CdeL. The inverse relation between fish consumption and 20 year mortality from coronary heart disease. N Engl f Med 1985;312:1205-9.

11 Mann JI, Thorogood M. Serum lipids in young female survivors of myocardial infarctions. Br Hearif 1975;37:790-4.

12 Payne CD, ed. Generalised linear interactive modelling system. London: Royal Statistical Society, 1985.

13 Flynn FV, Piper KAJ, Garcia-Webb P, McPherson CK, Healy MJR. The frequency distributions of commonly determined blood constituents in healthy blood donors. Clin Chim Acte 1974;52:163-71.

14 Truswell AS, Mann JI. Epidemiology of serum lipids in southern Africa. Atherosclerosis 1972;16:15-29.

15 Mensink RP, Katan MB. Effect of monounsaturated fatty acids versus complex carbohydrates on high-density lipoproteins in healthy men and women. Lancet 1987;i:122-5.

16 Lewis B, Hammett F, Katan M, et al. Towards an improved lipid lowering diet: additive effects of changes in nutrient intake. Lancet 1981;i:1310-3.

17 Shekelle RB, Shryock AM, Oglesby P, et al. Diet, serum cholesterol and death from coronary heart disease: the Western Electric study. N Engl f Med 1981;304:65-70.

18 Pocock SJ, Shaper AG, Phillips AN, Walker M, Whitehead TP. High density lipoprotein cholesterol is not a major risk factor for ischaemic heart disease in British men. Br Med $\mathcal{J}$ 1986;292:515-9.

19 Lipid Research Clinics Program Epidemiology Committee. Plasma lipid distributions. Circulation 1979;60:427-39.

20 McPherson K, Healy MJR, Flynn FV, Piper KAJ, Garcia-Webb P. The effect of age, sex and other factors on blood chemistry in health. Clin Chim Acta 1978;84:373-97.

21 Miller NE. Why does plasma low density lipoprotein concentration in adults increase with age? Lancet 1984;i:263-6.

(Accepted 11 fune 1987) 